\title{
Prejudicial and Stereotypical Attitudes about the Issue of Obesity: An Action Project
}

\author{
Maria Elvira De Caroli, Elisabetta Sagone, Orazio Licciardello, Zira Hichy \\ Department of Educational Sciences, University of Catania, Catania, Italy \\ Email: m.decaroli@unict.it
}

How to cite this paper: De Caroli, M. E., Sagone, E., Licciardello, O., \& Hichy, Z (2017). Prejudicial and Stereotypical Attitudes about the Issue of Obesity: An Action Project. Psychology, 8, 2174-2186. https://doi.org/10.4236/psych.2017.813138

Received: September 9, 2017

Accepted: November 26, 2017

Published: November 29, 2017

Copyright ( $) 2017$ by authors and Scientific Research Publishing Inc. This work is licensed under the Creative Commons Attribution International License (CC BY 4.0).

http://creativecommons.org/licenses/by/4.0/

Open Access

\begin{abstract}
Scientific literature about stereotypical and prejudicial attitudes toward obese people indicates rejection toward the obese individuals and preferences toward thin and average ones, as well as a stereotypical profile that attributes to obese people traits such as weakness, laziness, and sickness, while to thin and average people characteristics as beauty, strength, health, and successfulness (Tiggemann \& Anesbury, 2000; Carels \& Musher-Eizenman, 2010). One of the most useful strategies for reducing the effects of negative prejudices and stereotypes toward the obesity and obese people is constituted by contact, achievable both in face to face and imagined setting. Purpose: analysis of the exposure effects to stimuli (training course about prejudice on obesity) functional to reduce negative attitudes toward obese people. Participants: 55 psychology university students at University of Catania, Sicily (Italy). Implicit and explicit measures: 1) Anti-fat Attitudes and Dislike of Fat People Scale; 2) Semantic Differential Technique for Fat and Thin People Representation and Physical Self; 3) Fat Stereotypes Questionnaire; 4) GNAT (Nosek \& Banaji, 2001). All measures were used before and after the training course (for three months) about the "obesity issue". Results (before-after the training course): a) low levels of anti-fat prejudice and of dislike of fat people; b) absence of change of fat stereotypes; c) significant increase in fat and thin people positive representation, as well as in self-representation; d) significant effects of the training course only in relation to an increase of accuracy in the GNAT application. Future suggestions regarding to the effects of the direct and imagined contact with obese people functional to reduce negative attitudes toward these target were discussed.
\end{abstract}

\section{Keywords}

Obesity, Prejudice, Fat Stereotypes, University Students 


\section{Introduction}

A great amount of researches has documented the existence of anti-fat attitudes and negative stereotypes toward overweight and obese people from infancy to adulthood (Crandall, 1994; Cramer \& Steinwert, 1998; Morrison \& O'Connor, 1999; Tiggemann \& Anesbury, 2000; Puhl \& Brownell, 2001; Lowes \& Tiggemann, 2003; Musher-Eizenman, Holub, Miller, Goldstein, \& Edwards-Leeper, 2004; O’Brien, Hunter, \& Banks, 2007; Carels \& Musher-Eizenman, 2010; Vartanian, 2010; Carels et al., 2013). Several evidences demonstrated that children chose overweight children less than average-weight ones and wished to interact with them less than with average-weight target children (Bell \& Morgan, 2000), also preferring normal-weight or thin peers as best friends and playmates more frequently than overweight peers (Musher-Eizenman et al., 2004; Margulies, Floyd, \& Hojnoski, 2008). As indicated by Margulies and colleagues (Margulies et al., 2008), when children were shown a large number of drawings depicting underweight, average-weight, and overweight child and asked to select three playmates and a best friend, they chose the average-weight and thin children as friends and playmates significantly more often than the overweight ones. Additionally, Bell \& Morgan (2000), as well as Greenleaf and colleagues (Greenleaf et al., 2006), found that children were less likely to choose overweight peers as partners in school-related activities and were less likely to interact with them in social-recreational activities in relation to the belief according to which the target child would be able to execute the favorite activity. Finally, Anesbury \& Tiggeman (2000) investigated the reduction of negative attitudes toward fat people as a result of the modification of children's beliefs about the controllability of obesity expressed by children from 9 to 11 years old; children of the experimental group were exposed to a brief intervention focused on the uncontrollability of weight, observing that the intervention was successful in reducing the amount of controllability that children associated to obesity, but it was not successful in reducing negative stereotypes toward the obese compared to the control group. These results revealed that while children's beliefs about the controllability of obesity can be modified, their negative stereotyping is more difficult to reduce.

In reference to adulthood, many studies demonstrated that the factors which affect the development of negative social attitudes toward obese people are often represented by perceptual reliance and beliefs about the controllability of weight (Carels \& Musher-Eizenman, 2010; Flint, Hudson, \& Lavallee, 2015), fat-stereotypical beliefs and stigma (Bessenoff \& Sherman, 2000; Ciao \& Latner, 2011), physical attractiveness and body mass index (Tovée \& Cornelissen, 2001; Swami \& Tovée, 2005; Vartanian, 2010), and perception of body image (Lewis et al., 1997; O'Brien et al., 2007). For example, more recently, using vignettes describing the causes of obesity into three different experimental situations (individual, environmental, and genetic factors) and semantic differential about people with obesity, Luck-Sikorski, Riedel-Heller, \& Phelan (2017) found that participants who 
received an individual-based explanation for obesity displayed the highest levels of negative attitudes, while those who received a genetic explanation showed the lowest levels of negative attitudes. About the reduction of obesity stigma in undergraduate university students, Ciao \& Latner (2011) found that interventions focused on "cognitive dissonance" (that is, high discrepancy between personal value priorities and obesity stigma) may be successful in changing negative attitudes about the appearance and attractiveness of obese people and reducing the obesity stigma more than the "social consensus" interventions. Finally, with the application of "imagined contact hypothesis" (see Crisp \& Turner, 2009; Crisp \& Turner, 2012), according to which mentally simulating a positive interaction with an outgroup member can elicit more favorable explicit and implicit attitudes, less stereotyping, and enhance dispositions to engage in future contact, Turner \& West (2012) observed that university students who believed that they will be involved in an interaction for a discussion with an obese person placed the chairs closer together (measure of physical immediacy) and reduced social distance. This type of indirect contact seemed to prepare individuals to the face-to-face contact.

Findings from several studies indicated that positive traits were assigned to thin people more frequently than to obese or overweight people; in addition, the more the individuals expressed anti-fat prejudice and propensity to judge the others in relation to their own physical appearance ("perceptual reliance"), the more they tended to show negative attitudes toward overweight people. People who believe that weight is a controllable factor displayed more negative attitudes toward the obese and extremely obese individuals than people who believed that weight is not a controllable factor.

With reference to the role of stereotyped beliefs, empirical evidences showed that children, adolescents, and adults displayed negative stereotypes toward overweight and obese individuals by attributing more negative (e.g., lazy, slow, gross, unattractive) and fewer positive traits to fat people (Greenleaf et al., 2004) than to thin and normal-weight people (Brochu \& Morrison, 2007). As found by Tiggemann \& Wilson-Barrett (1998), Davison \& Birch (2004), and Harriger et al. (2010), overweight body pictures were valued by children as more mean, sick, ugly, stupid, dirty, lazy, and sloppy, and less smart, happy, popular and attractive than normal-weight ones. In relation to these dimensions, the authors of the current project explored social attitudes and stereotyped beliefs toward fat people, carrying out two recent studies, respectively, one with female Italian university students, using the Anti-fat Attitudes Scale and Dislike of Fat People Scale, Semantic Differentials for the representation of Fat People, Thin People, and Self-Concept, and Fat Stereotypes Questionnaire (see De Caroli \& Sagone, 2013), and the other with Italian pupils aged from 5 to 10 (Sagone \& De Caroli, 2013), utilizing the Anti-fat Attitudes Scale, the choice of best friend and classmate and the rejection referred to recreational activities, and Fat Stereotypes Questionnaire. For university students, results showed that they expressed low 
levels of anti-fat attitudes and of dislike of fat people; a positive representation of fat people was associated with low levels of anti-fat prejudice and positive stereotyped beliefs toward fat people; finally, over $70 \%$ of students attributed to fat people mainly positive traits linked to happiness, sweetness, kindness, and generosity. For pupils, results revealed that they attributed negative characteristics to overweight and positive traits to normal-weight peers and expressed negative attitudes toward overweight peers; they chose normal-weight and underweight peers as best friends/classmates and rejected overweight peers for recreational activities; finally, pupils who expressed negative attitudes toward overweight peers chose underweight peers as best friends/classmates and rejected overweight ones.

Considering the previous findings about the implicit and explicit persistence of obesity stigma and negative prejudicial and stereotyped attitudes toward obese people in Italian context, the rationale of this project was to modify the direction of these attitudes in university students by means of a training course focused on the "obesity issue".

\section{Methodology}

The current project was developed in light of the fact that one of the most useful strategies for reducing the discriminate effects of negative prejudices and stereotypes toward the obesity phenomenon and obese people as negative target is constituted by contact, qualitatively effective and quantitatively efficient, achievable both in face to face and imagined setting. For this reason, this project was focused on the effects of the exposure to activities functional to reduce stereotypical and prejudicial attitudes toward obese people, that is, the application of "contact hypothesis" (Allport, 1954; Brown \& Hewstone, 2005; Pettigrew \& Tropp, 2006), and specifically, of the "imagined contact hypothesis" (Crisp \& Turner, 2009). We adopted implicit and explicit measures of social attitudes toward obese people, as recently reported by Flint and other colleagues (Flint et al., 2015). So, we hypothesized that the exposure of university students to "imagined contact" with obese people would modify these explicit and implicit attitudes and the representation of obese people $\left(\mathrm{H}_{1}\right)$; in addition, we hypothesized that the "imagined contact" with obese people would change the fat stereotypes beliefs $\left(\mathrm{H}_{2}\right)$.

\subsection{Participants}

The chosen sample of this project consisted of 55 university students (range age: 22 - 30 yrs) attending an introductory psychology course at Department of Educational Sciences, University of Catania, Sicily (Italy), predominantly girls $(n=$ 49) with body mass index (BMI) ranged from 18.5 to $25 \mathrm{~kg} / \mathrm{m}^{2}$ classified as normal weight based upon self-reported height and weight. The composition of sample depends on the fact that psychology course is mainly attended by female university students. Informed consent was obtained from all participants who took part in the study. 


\subsection{Measures}

a) Demographic information. All participants completed background questions related to gender, age, weight and height, and physical exercise.

b) The Anti-fat Attitudes (AFAS) and Dislike of Fat People Scale (DFPS) were used to analyze the explicit anti-fat prejudice (De Caroli \& Sagone, 2013). Ten items were included in the AFAS: e.g., "Fat people are less sexually attractive than other people", "Fat people have only themselves to blame for their weight". Fourteen items were included in the DFPS: e.g., "If I were an employer looking to hire someone, I might avoid hiring a fat person", "I don't have many friends which are fat". Participants responded to each of the 24 items on a 5-point Likert scale ranging from 1 (anchored with "strongly disagree") to 5 intervals (anchored with "strongly agree"). High mean scores expressed high levels of anti-fat prejudice and dislike toward fat people.

c) The Fat Stereotypes Questionnaire (FSQ) was adopted to study the stereotyped beliefs toward obese people (De Caroli \& Sagone, 2013): this measure included 11 positive and 11 negative traits referred to psychological (e.g., happy, shy, generous, honest) and physical features (e.g., weak, hungry, aggressive). Participants were asked to attribute, using the forced choice format, each of the 22 characteristics to one of two photos of the same target, respectively, in overweight and normal-weight version (female target for female participants and male target for male ones). By mean of this measure, it is possible to obtain the amount of "pro-fat stereotypes" or "anti-fat stereotypes", computing the number of positive or negative traits associated to fat or obese targets.

d) The Semantic Differentials were utilized to analyze the representation of the following three concepts (Bacon, Scheltema, \& Robinson, 2001; De Caroli \& Sagone, 2015): physical self, overweight people, and normal-weight people. These measures consisted of 36 pairs of opposite adjectives for each concept (e.g., weak vs. strong; desirable vs. undesirable), each evaluable on a 7-point Likert scale. High mean scores expressed a positive representation of physical self-image, overweight, and normal-weight people.

e) The Implicit Association Test (IAT) (see Greenwald, McGhee, \& Schwartz, 1998; Greenwald, Nosek, \& Banaji, 2003) was the implicit measure used to analyze the implicit attitudes towards fatness and thinness (see Teachman \& Brownell, 2001; Vartanian, Herman, \& Polivy, 2005). Participants were presented with weight-related words and associated these as quickly as possible with different grouping categories. In this study, we used the GNAT version (Go/Not go Association Task) proposed by Nosek and Banaji (2001); see also Nosek, Greenwald, \& Banaji (2005). Firstly, participants completed four practice blocks to introduce themselves with the task. In these practice blocks they learned to discriminate, in the order, thin (from obese), obese (from thin), positive (from negative), and negative (from positive); for each block, 16 trials were presented (eight targets and eight distracters). After the practice blocks, participants completed four randomized blocks (obese + positive, obese + negative, thin + positive, and thin + negative) and, for each block consisting of 40 trials, the target category (e.g., 
obese) was paired with an attribute (e.g., positive). Participants were instructed to press the spacebar when items belonging to labeled categories appeared on the screen or to do nothing when items which did not belong to these categories appeared on the screen. The words utilized for each category are the following: obese, overweight, chest, corpulent, bark, adipose, round, and paunchy (for Fat category); thin, underweight, mild, slight, slender, minute, lean, and skinny (for Thin category); joyful, cheerful, beautiful, good, funny, pleasant, happy, and wonderful (for Positive category); disgusting, painful, ugly, bad, disastrous, terrible, horrible, and scary (for Negative category).

\subsection{Procedure}

This project was divided in three phases. After the exploration of stereotypical and prejudicial attitudes expressed by university students toward obese and thin people, using the abovementioned implicit and explicit measures (first phase; pre-training course), we proceeded to realize the activities (film projection, focus groups) functional to modification of initially measured attitudes and included in the training course focused on the prejudice about the "obesity issue" (intermediate phase); subsequently, we re-administered to all participants the measures used at the start of the project verifying the efficacy of actions during the training course (third phase; post-training course).

\subsection{Data Analysis}

Mean scores were calculated for all measures and used in the following statistical analyses by means of SPSS v20. All measures were applied before and after the training course (for a period of three months) about the "obesity issue", analyzing the statistical differences with t-tests. With regard to the GNAT, the d-prime was calculated according to the approach defined by Nosek \& Banaji (2001) as well as by Banaji \& Greenwald (1995): 1) the proportion of correct "go" response for signal items (hits) and incorrect "go" response for noise items (false alarms) were each converted to $\mathrm{z}$-scores; 2) a difference between the $\mathrm{z}$-score values for hits and false alarms is d'.

\section{Results}

Results indicated that all psychology university students (mainly, girls) expressed low levels of anti-fat prejudice (AFAS: pre-training: $\mathrm{M}=2.86$, sd $=0.23$; post-training: $\mathrm{M}=2.91$, sd $=0.21$ ) and dislike of fat people (DFPS: pre-training: $M=2.93, s d=0.17$; post-training: $M=2.95$, sd $=0.18$, without significant differences after the exposure to imagined contact situations with obese people during training activities (AFAS: $t_{(54)}=-1.58, p=0.12 n s$, DFPS: $t_{(54)}=-0.87, p=$ $0.38 \mathrm{~ns}$ ), displaying scarcely negative attitudes toward obese people.

Similar results in relation to the effects of training course were observed about the absence of change of fat stereotypes both for female target (pre-training: $\mathrm{M}=$ 7.74 , sd $=2.24$; post-training: $\mathrm{M}=7.65$, sd $\left.=1.71 ; t_{(54)}=0.39, p=0.70 \mathrm{~ns}\right)$ and for male target (pre-training: $M=6.36$, $s d=2.58$; post-training: $M=6.29$, $s d=$ 
$\left.2.97 ; t_{(54)}=0.21, p=0.83 n s\right)$. In detail, before the training course, the majority of psychology university students associated to the fat female target both negative traits, as rejected, lazy, slow, weak, shy, sick, and positive traits, as happy, sweet, playful, honest, kind, quite, and generous. After the training course, comparable results were found (Table 1 ).

For the other target (Table 2), results showed that, before the training course, the fat male target was characterized by the same positive and negative traits associated to the fat female one, except for hungry and whiner; also in this case, analogous results were found after the training course.

Using semantic differential technique (Table 3 ), results showed a significant increase in fat $\left(t_{(54)}=-4.40, p<0.001\right)$ and thin $\left(t_{(54)}=-8.12, p<0.001\right)$ people positive representation, as well as in physical self-representation $\left(t_{(54)}=-15.60, p<\right.$ 0.001 ); so, psychology students expressed a more positive representation of fat and thin people and of themselves than the one expressed before the training course.

Table 1. Fat stereotypes for female target: comparison between pre- and post-training.

\begin{tabular}{|c|c|c|c|c|c|c|c|c|}
\hline \multirow{3}{*}{ Traits for female target } & \multicolumn{4}{|c|}{ Before contact Pre-training } & \multicolumn{4}{|c|}{ After contact Post-training } \\
\hline & \multicolumn{2}{|c|}{ Fat } & \multicolumn{2}{|c|}{ Normal-weight } & \multicolumn{2}{|c|}{ Fat } & \multicolumn{2}{|c|}{ Normal-weight } \\
\hline & $\mathrm{N}$ & $\%$ & $\mathrm{~N}$ & $\%$ & $\mathrm{~N}$ & $\%$ & $\mathrm{~N}$ & $\%$ \\
\hline Happy & 52 & 94.5 & 3 & 5.5 & 47 & 85.5 & 8 & 14.5 \\
\hline Hungry & 30 & 54.5 & 25 & 45.5 & 36 & 65.5 & 19 & 34.5 \\
\hline Sweet & 47 & 85.5 & 8 & 14.5 & 51 & 92.7 & 4 & 7.3 \\
\hline Rejected & 48 & 87.3 & 7 & 12.7 & 46 & 83.6 & 9 & 16.4 \\
\hline Lazy & 42 & 76.4 & 13 & 23.6 & 40 & 72.7 & 15 & 27.3 \\
\hline Whiner & 29 & 52.7 & 26 & 47.3 & 30 & 54.4 & 25 & 45.5 \\
\hline Aggressive & 6 & 10.9 & 49 & 89.1 & 8 & 14.5 & 47 & 85.5 \\
\hline Unpleasant & 4 & 7.3 & 51 & 92.7 & 4 & 7.3 & 51 & 92.7 \\
\hline Playful & 49 & 89.1 & 6 & 10.9 & 49 & 89.1 & 6 & 10.9 \\
\hline Intelligent & 31 & 56.4 & 24 & 43.6 & 29 & 52.7 & 26 & 47.3 \\
\hline Courageous & 24 & 43.6 & 31 & 56.4 & 23 & 41.8 & 32 & 58.2 \\
\hline Self-confident & 8 & 14.5 & 47 & 85.5 & 7 & 12.7 & 48 & 87.3 \\
\hline Bossy & 7 & 12.7 & 48 & 87.3 & 6 & 10.9 & 49 & 89.1 \\
\hline Honest & 44 & 80.0 & 11 & 20.0 & 46 & 83.6 & 9 & 16.4 \\
\hline Slow & 51 & 92.7 & 4 & 7.3 & 52 & 94.5 & 3 & 5.5 \\
\hline To fulfill promises & 32 & 58.2 & 23 & 41.8 & 31 & 56.4 & 24 & 43.6 \\
\hline Weak & 42 & 76.4 & 13 & 23.6 & 42 & 76.4 & 13 & 23.6 \\
\hline Kind & 47 & 85.5 & 8 & 14.5 & 50 & 90.9 & 5 & 9.1 \\
\hline Quiet & 40 & 72.7 & 15 & 27.3 & 42 & 76.4 & 13 & 23.6 \\
\hline Shy & 41 & 74.5 & 14 & 25.5 & 43 & 78.2 & 12 & 21.8 \\
\hline Generous & 47 & 85.5 & 8 & 14.5 & 46 & 83.6 & 9 & 16.4 \\
\hline Sick & 42 & 76.4 & 13 & 23.6 & 41 & 74.5 & 14 & 25.5 \\
\hline
\end{tabular}


M. E. De Caroli et al.

Table 2. Fat stereotypes for male target: comparison between pre- and post-training.

\begin{tabular}{|c|c|c|c|c|c|c|c|c|}
\hline \multirow{3}{*}{ Traits for male target } & \multicolumn{4}{|c|}{ Before contact Pre-training } & \multicolumn{4}{|c|}{ After contact Post-training } \\
\hline & \multicolumn{2}{|c|}{ Fat } & \multicolumn{2}{|c|}{ Normal-weight } & \multicolumn{2}{|c|}{ Fat } & \multicolumn{2}{|c|}{ Normal-weight } \\
\hline & $\mathrm{N}$ & $\%$ & $\mathrm{~N}$ & $\%$ & $\mathrm{~N}$ & $\%$ & $\mathrm{~N}$ & $\%$ \\
\hline Happy & 35 & 63.6 & 20 & 36.4 & 38 & 69.1 & 17 & 30.9 \\
\hline Hungry & 43 & 78.2 & 12 & 21.8 & 45 & 81.8 & 10 & 18.2 \\
\hline Sweet & 37 & 67.3 & 18 & 32.7 & 36 & 65.5 & 19 & 34.5 \\
\hline Rejected & 52 & 94.5 & 3 & 5.5 & 51 & 92.7 & 4 & 7.3 \\
\hline Lazy & 47 & 85.5 & 8 & 14.5 & 49 & 89.1 & 6 & 10.9 \\
\hline Whiner & 41 & 74.5 & 14 & 25.5 & 38 & 69.1 & 17 & 30.9 \\
\hline Aggressive & 14 & 25.5 & 41 & 74.5 & 18 & 32.7 & 37 & 67.3 \\
\hline Unpleasant & 12 & 21.8 & 43 & 78.2 & 11 & 20.0 & 44 & 80.0 \\
\hline Playful & 47 & 85.5 & 8 & 14.5 & 46 & 83.6 & 9 & 16.4 \\
\hline Intelligent & 23 & 41.8 & 32 & 58.2 & 27 & 49.1 & 28 & 50.9 \\
\hline Courageous & 22 & 40.0 & 33 & 60.0 & 19 & 34.5 & 36 & 65.5 \\
\hline Self-confident & 8 & 14.5 & 47 & 85.5 & 12 & 21.8 & 43 & 78.2 \\
\hline Bossy & 13 & 23.6 & 42 & 76.4 & 10 & 18.2 & 45 & 81.8 \\
\hline Honest & 38 & 69.1 & 17 & 30.9 & 33 & 60.0 & 22 & 40.0 \\
\hline Slow & 52 & 94.5 & 3 & 5.5 & 51 & 92.7 & 4 & 7.3 \\
\hline To fulfill promises & 24 & 43.6 & 31 & 56.4 & 26 & 47.3 & 29 & 52.7 \\
\hline Weak & 42 & 76.4 & 13 & 23.6 & 37 & 67.3 & 18 & 32.7 \\
\hline Kind & 38 & 69.1 & 17 & 30.9 & 35 & 63.6 & 20 & 36.4 \\
\hline Quiet & 37 & 67.3 & 18 & 32.7 & 35 & 63.6 & 20 & 36.4 \\
\hline Shy & 41 & 74.5 & 14 & 25.5 & 38 & 69.1 & 17 & 30.9 \\
\hline Generous & 41 & 74.5 & 14 & 25.5 & 39 & 70.9 & 16 & 29.1 \\
\hline Sick & 48 & 87.3 & 7 & 12.7 & 42 & 76.4 & 13 & 23.6 \\
\hline
\end{tabular}

Table 3. Semantic differentials: comparison between pre- and post-training.

\begin{tabular}{cccccc}
\hline \multirow{2}{*}{$\begin{array}{c}\text { Semantic } \\
\text { differentials }\end{array}$} & \multicolumn{2}{c}{ Before contact Pre-training } & \multicolumn{2}{c}{ After contact Post-training } & \multicolumn{2}{c}{ T-tests } \\
\cline { 2 - 5 } & Mean & sd & Mean & sd & ${ }^{\star} p<0.001$ \\
\hline Fat people & 3.85 & 0.21 & 4.31 & 0.64 & $-4.403^{\star}$ \\
Thin people & 3.72 & 0.22 & 4.50 & 0.60 & $-8.122^{*}$ \\
Physical Self & 3.64 & 0.22 & 4.88 & 0.56 & $-15.602^{*}$ \\
\hline
\end{tabular}

*The significance value for $p<0.001$.

With regard to the first administration, by means of the GNAT (Table 4), results showed a significant interaction weight $\mathrm{x}$ valence $\left[F_{(1,54)}=36.54, p<0.001\right.$, $\left.\eta^{2}=0.40\right]$ and the post hoc analyses indicated more positive attitudes toward thin people than toward fat people $(p<0.05)$. The same results emerged in the second administration; also in this case, a significant interaction weigh $\mathrm{x}$ valence 
Table 4. GNAT: comparison between pre- and post-training.

\begin{tabular}{ccccc}
\hline \multirow{2}{*}{ GNAT } & \multicolumn{2}{c}{ Before contact Pre-training } & \multicolumn{2}{c}{ After contact Post-training } \\
\cline { 2 - 5 } & Mean & sd & Mean & sd \\
\hline Negative obese & 0.93 & 0.61 & 1.10 & 0.63 \\
Positive obese & 0.74 & 0.48 & 0.88 & 0.59 \\
Negative thin & 0.49 & 0.50 & 0.84 & 0.62 \\
Positive thin & 1.13 & 0.63 & 1.24 & 0.64 \\
\hline
\end{tabular}

was found $\left[F_{(1,54)}=22.90, p<0.001, \eta^{2}=0.30\right]$ and post hoc analyses showed more positive attitudes toward thin people than toward fat people $(p<0.05)$. Finally, with regards to the effect of the intervention focused on the imagined contact with obese people, results indicated that it was significant $\left[F_{(1,54)}=18.37\right.$, $\left.p<0.001, \eta^{2}=0.25\right]$ and post hoc analyses pointed out an increase in both positive and negative attitudes toward fat people and negative attitudes toward thin people $(p<0.05)$.

\section{Discussion}

The main purpose of the current study was to verify the influence of imagined contact with obese and fat people during training course on prejudicial attitudes toward these social groups $\left(\mathrm{H}_{1}\right)$ and stereotypical beliefs $\left(\mathrm{H}_{2}\right)$ about the "obesity issue" in psychology university students. We expected that this type of contact would improve the explicit and implicit attitudes and the representation of obese people, reducing the negative prejudice toward these groups $\left(\mathrm{H}_{1}\right)$; in addition, we expected that the imagined contact with obese people would change the fat stereotypes beliefs $\left(\mathrm{H}_{2}\right)$, modifying the typical and shared ideas about these groups passing from negative to positive representation of them.

Results indicated that all psychology university students displayed low levels of anti-fat attitudes and dislike of fat people both before and after the imagined contact with fat or obese people and training course about the "obesity issue". These evidences were consistently similar to previous results obtained by De Caroli \& Sagone (2013) and this datum could be due to gender composition of sample, predominantly consisting of girls. As recently found in Flint and his colleagues' research in UK population (2015), females reported less negative attitudes toward obese people (ATOP-Attitudes toward Obese Persons Scale: Allison, Basile, \& Yuker, 1991), less anti-fat attitudes (AFAS), and less fat phobia than males, but showed stronger beliefs that obesity is controllable condition (BAOP-Beliefs about Obese Persons Scale; see Allison et al., 1991) and perceived the words "fat" and "obese" (IAT) as more insulting. Additionally, according to the sex differences in the expression of anti-fat attitudes, many studies found that men and boy showed greater anti-fat attitudes than women and girls (Hebl et al., 2008; Latner et al., 2008; Puhl, Andreyeva, \& Brownell, 2008; Wang, Brownell, \& Wadden, 2004).

In relation to the fat stereotypes, the typical negative ideas about obese or fat 
people remained the same after the imagined contact during the training course (see De Caroli \& Sagone, 2013). So, both for female and male target, the negative traits of sickness, shyness, weakness, slowness, laziness, and rejection from other people seemed to be typical features of the obese people profile, even if it was possible to note also the presence of positive traits characterizing the same profile, such as happiness, sweetness, playfulness, honesty, kindness, quietness, and generousness.

The unique change emerged in relation to the usage of semantic differentials about obese and thin people; so, results demonstrated that psychology university students expressed a more positive representation of fat and thin people and of their physical self than the one expressed before the training course, partially confirming the initial $\mathrm{H}_{1}$.

The unexpected absence of modification in relation to explicit prejudicial attitudes (AFAS and DFPS) and implicit measure (GNAT) after the training course-inspired to imagined contact hypothesis puts into consideration the possible reduced effect of this procedure compared to the face-to-face and direct contact with obese people in social and academic contexts.

\section{Conclusion}

Among the limits of the present study, it is possible to point out the necessity: 1) to replicate this investigation with a large number of Italian university students, balanced for gender composition, to obtain the representativeness of the sample; 2) to compare experimental group (under the training course focused on the "obesity issue") with control group in order to verify the modification of prejudicial and stereotypical attitudes.

Future investigations could be carried out using samples balanced for sex, consisting of university students attending different types of degree courses (for example, Medicine, Physical Exercise Sciences, Food and Nutritional Sciences), in order to analyze the social attitudes towards obese people expressed by boys and girls and by future specialized workers interested in the obesity phenomenon. Furthermore, it could be more useful to adopt both direct and imagined contact with obese or fat people to assess the differences between the two types of experiences of contact with these social groups and their effects on changing prejudicial and stereotypical attitudes.

\section{Acknowledgements}

This work was supported by FIR 2014 Grant Project No. 22AC6D at the University of Catania, Sicily (Italy) in relation to the European Research CouncilERC, SH4_2 (Human Life-span development), SH4_5 (Social Psychology), and LS9_5 (Food Sciences).

\section{References}

Allison, D. B., Basile, V. C., \& Yuker, H.E. (1991) The Measurement of Attitudes and Be- 
liefs about Obese Persons. International Journal of Eating Disorders, 10, 599-607.

Allport, G. W. (1954). The Nature of Prejudice. Cambridge: Addison-Wesley Publishing Company.

Anesbury, T., \& Tiggemann, M. (2000). An Attempt to Reduce Negative Stereotyping of Obesity in Children by Changing Controllability Beliefs. Health Education Research, 15, 145-152. https://doi.org/10.1093/her/15.2.145

Bacon, J. G., Scheltema, K. E., \& Robinson, B. E. (2001). Fat Phobia Scale Revisited: The Short Form. International Journal of Obesity, 25, 252-257. https://doi.org/10.1038/sj.ijo.0801537

Banaji, M. R., \& Greenwald, A. G. (1995). Implicit Gender Stereotyping in Judgments of Fame. Journal of Personality and Social Psychology, 68, 181-198. https://doi.org/10.1037/0022-3514.68.2.181

Bell, S., \& Morgan, S. (2000). Children's Attitudes and Behavioral Intentions toward a Peer Presented as Obese: Does a Medical Explanation for the Obesity Make a Difference? Journal of Pediatric Psychology, 25, 137-145.

https://doi.org/10.1093/jpepsy/25.3.137

Bessenoff, G. R., \& Sherman, J. W. (2000). Automatic and Controlled Components of Prejudice toward Fat People: Evaluation versus Stereotype Activation. Social Cognition, 18, 329-353. https://doi.org/10.1521/soco.2000.18.4.329

Brochu, P. M., \& Morrison, M. A. (2007). Implicit and Explicit Prejudice toward Overweight and Average-Weight Men and Women: Testing Their Correspondence and Relation to Behavioral Intentions. The Journal of Social Psychology, 147, 681-706. https://doi.org/10.3200/SOCP.147.6.681-706

Brown, R., \& Hewstone, M. (2005). An Integrative Theory of Intergroup Contact. Advances in Experimental Social Psychology, 37, 255-343. https://doi.org/10.1016/S0065-2601(05)37005-5

Carels, R. A., \& Musher-Eizenman, D. R. (2010). Individual Differences and Weight Bias: Do People with an Anti-Fat Bias Have a Pro-Thin Bias? Body Image, 7, 143-148. https://doi.org/10.1016/j.bodyim.2009.11.005

Carels, R. A., Hinman, N. G., Burmeister, J. M., Hoffman, D. A., Ashrafioun, J., \& Koball, A. M. (2013). Stereotypical Images and Implicit Weight Bias in Overweight/Obese People. Eating and Weight Disorders, 18, 441-445. https://doi.org/10.1007/s40519-013-0072-5

Ciao, A. C., \& Latner, J. D. (2011). Reducing Obesity Stigma: The Effectiveness of Cognitive Dissonance and Social Consensus Interventions. Obesity, 19, 1768-1774. https://doi.org/10.1038/oby.2011.106

Cramer, P., \& Steinwert, T. (1998). Thin Is Good, Fat Is Bad: How Early Does It Begin? Journal of Applied Developmental Psychology, 19, 429-451. https://doi.org/10.1016/S0193-3973(99)80049-5

Crandall, C. S. (1994). Prejudice against Fat People: Ideology and Self-Interest. Journal of Personality and Social Psychology, 66, 882-894. https://doi.org/10.1037/0022-3514.66.5.882

Crisp, R. J., \& Turner, R. N. (2009). Can Imagined Interactions Produce Positive Perceptions? Reducing Prejudice through Simulated Social Contact. American Psychologist, 64, 231-240. https://doi.org/10.1037/a0014718

Crisp, R. J., \& Turner, R. N. (2012). Imagined Intergroup Contact. In G. Hodson, \& M. Hewstone (Eds.), Advances in Intergroup Contact (pp. 135-151). Hove: Psychology Press, Taylor \& Francis.

Davison, K., \& Birch, L. (2004). Predictors of Fat Stereotypes among 9-Year-Old Girls 
and Their Parents. Obesity Research, 12, 86-94. https://doi.org/10.1038/oby.2004.12

De Caroli, M. E., \& Sagone, E. (2013). Anti-Fat Prejudice and Stereotypes in Psychology University Students. Procedia-Social and Behavioral Sciences, 84, 1184-1189. https://doi.org/10.1016/j.sbspro.2013.06.724

De Caroli, M. E., \& Sagone, E. (2015). Anti-Fat Attitudes and Weight Stereotypes: A Comparison between Adolescents and Their Teachers. Procedia-Social and Behavioral Sciences, 191, 280-285. https://doi.org/10.1016/j.sbspro.2015.04.684

Flint, S. W., Hudson, J., \& Lavallee, D. (2015). UK Adults' Implicit and Explicit Attitudes towards Obesity: A Cross-Sectional Study. BMC Obesity, 2. https://doi.org/10.1186/s40608-015-0064-2

Greenleaf, C., Chambliss, H., Rhea, D. J., Martin, S. B., \& Morrow, J. R. (2006). Weight Stereotypes and Behavioral Intentions toward Thin and Fat Peers among White and Hispanic Adolescents. Journal of Adolescence Health, 39, 546-552. https://doi.org/10.1016/j.jadohealth.2006.01.013

Greenleaf, C., Starks, M., Gomez, L., Chambliss, H., \& Martin, S. (2004). Weight-Related Words Associated with Figure Silhouettes. Body Image, 1, 373-384. https://doi.org/10.1016/j.bodyim.2004.10.004

Greenwald, A. G., McGhee, D. E., \& Schwartz, J. L. K. (1998). Measuring Individual Differences in Implicit Cognition: The Implicit Association Test. Journal of Personality and Social Psychology, 74, 1464-1480. https://doi.org/10.1037/0022-3514.74.6.1464

Greenwald, A. G., Nosek, B. A., \& Banaji, M. R. (2003). Understanding and using the Implicit Association Test: An Improved Scoring Algorithm. Journal of Personality and Social Psychology, 85, 197-216. https://doi.org/10.1037/0022-3514.85.2.197

Harriger, J. A., Calogero, R. M., Witherington, D. C., \& Smith, J. E. (2010). Body Size Stereotyping and Internalization of the Thin Ideal in Preschool Girls. Sex Roles, 63, 609-620. https://doi.org/10.1007/s11199-010-9868-1

Hebl, M. R., Ruggs, E. N., Singletary, S. L., \& Beal, D. J. (2008). Perceptions of Obesity across the Lifespan. Obesity, 16, S46-S52. https://doi.org/10.1038/oby.2008.458

Latner, J. D., O’Brien, K. S., Durso, L. E., Brinkman, L. A., \& MacDonald, T. (2008). Weighing Obesity Stigma: The Relative Strength of Different Forms of Bias. International Journal of Obesity, 32, 1145-1152. https://doi.org/10.1038/ijo.2008.53

Lewis, R. J., Cash, T. F., Jacobi, L., \& Bubb-Lewis, C. (1997). Prejudice toward Fat People: The Development and Validation of the Anti-Fat Attitudes Test. Obesity Research, 5, 297-307. https://doi.org/10.1002/j.1550-8528.1997.tb00555.x

Lowes, J., \& Tiggemann, M. (2003). Body Dissatisfaction, Dieting Awareness and the Impact of Parental Influence in Young Children. British Journal of Health Psychology, 8, 135-147. https://doi.org/10.1348/135910703321649123

Luck-Sikorski, C., Riedel-Heller, S. G., \& Phelan, J. C. (2017). Changing Attitudes towards Obesity-Results from a Survey Experiment. BMC Public Health, 17. https://doi.org/10.1186/s12889-017-4275-y

Margulies, A. S., Floyd, R. G., \& Hojnoski, R. L. (2008). Body Size Stigmatization: An Examination of Attitudes of African American Preschool-Age Children Attending Head Start. Journal of Pediatric Psychology, 33, 487-496. https://doi.org/10.1093/jpepsy/jsm082

Morrison, T. G., \& O’Connor, W. E. (1999). Psychometric Properties of a Scale Measuring Negative Attitudes toward Overweight Individuals. The Journal of Social Psychology, 139, 436-445. https://doi.org/10.1080/00224549909598403

Musher-Eizenman, D. R., Holub, S. C., Miller, A. B., Goldstein, S. E., \& Edwards-Leeper, L. (2004). Body Size Stigmatization in Preschool Children: The Role of Control Attri- 
butions. Journal of Pediatric Psychology, 29, 613-620.

https://doi.org/10.1093/jpepsy/jsh063

Nosek, B. A., \& Banaji, M. R. (2001). The Go/No-Go Association Task. Social Cognition, 19, 625-666. https://doi.org/10.1521/soco.19.6.625.20886

Nosek, B. A., Greenwald, A. G., \& Banaji, M. R. (2005). Understanding and using the Implicit Association Test: II. Method Variables and Construct Validity. Personality and Social Psychology Bulletin, 31, 166-180. https://doi.org/10.1177/0146167204271418

O’Brien, K. S., Hunter, J. A., \& Banks, M. (2007). Implicit Anti-Fat Bias in Physical Educators: Physical Attributes, Ideology and Socialization International Journal of Obesity, 31, 308-314. https://doi.org/10.1038/sj.ijo.0803398

Pettigrew, T. F., \& Tropp, L. R. (2006). A Meta-Analytic Test of Intergroup Contact Theory. Journal of Personality and Social Psychology, 90, 751-783. https://doi.org/10.1037/0022-3514.90.5.751

Puhl, R. M., Andreyeva, T., \& Brownell, K. D. (2008). Perceptions of Weight Discrimination: Prevalence and Comparison to Race and Gender Discrimination in America. International Journal of Obesity, 32, 992-1000. https://doi.org/10.1038/ijo.2008.22

Puhl, R., \& Brownell, K. D. (2001). Bias, Discrimination and Obesity. Obesity, 9, 788-805. https://doi.org/10.1038/oby.2001.108

Sagone, E., \& De Caroli, M. E. (2013). Anti-Fat or Anti-Thin Attitudes toward Peers? Stereotyped Beliefs and Weight Prejudice in Italian Children. Procedia-Social and Behavioral Sciences, 93, 177-183. https://doi.org/10.1016/j.sbspro.2013.09.174

Swami, V., \& Tovée, M. J. (2005). Female Physical Attractiveness in Britain and Malaysia: A Cross-Cultural Study. Body Image, 2, 115-128.

https://doi.org/10.1016/j.bodyim.2005.02.002

Teachman, B. A., \& Brownell, K. D. (2001). Implicit Anti-Fat Bias among Health Professionals: Is Anyone Immune? International Journal of Obesity, 25, 1525-1531. https://doi.org/10.1038/sj.ijo.0801745

Tiggemann, M., \& Anesbury, T. (2000). Negative Stereotyping of Obesity in Children: The Role of Controllability Beliefs. Journal of Applied Social Psychology, 30, 1977-1993. https://doi.org/10.1111/j.1559-1816.2000.tb02477.x

Tiggemann, M., \& Wilson-Barrett, E. (1998). Children's Figure Ratings: Relationship to Self-Esteem and Negative Stereotyping. International Journal of Eating Disorders, 23, 83-88.

https://doi.org/10.1002/(SICI)1098-108X(199801)23:1<83::AID-EAT10>3.0.CO;2-O

Tovée, M. J., \& Cornelissen, P. L. (2001). Female and Male Perceptions of Female Physical Attractiveness in Front-View and Profile. British Journal of Psychology, 92, 391-402. https://doi.org/10.1348/000712601162257

Turner, R. N., \& West, K. (2012). Behavioural Consequences of Imagining Intergroup Contact with Stigmatized Outgroups. Groups Processes \& Intergroup Relations, 15, 193-202. https://doi.org/10.1177/1368430211418699

Vartanian, L. R. (2010). Disgust and Perceived Control in Attitudes toward Obese People. International Journal of Obesity, 34, 1302-1307. https://doi.org/10.1038/ijo.2010.45

Vartanian, L. R., Herman, C. P., \& Polivy, J. (2005). Implicit and Explicit Attitudes towards Fatness and Thinness: The Role of the Internalization of Societal Standards. Body Image, 2, 373-381. https://doi.org/10.1016/j.bodyim.2005.08.002

Wang, S. S., Brownell, K. D., \& Wadden, T. A. (2004). The Influence of the Stigma of Obesity on Overweight Individuals. International Journal of Obesity and Related Metabolic Disorders, 28, 1333-1337. https://doi.org/10.1038/sj.ijo.0802730 